\title{
Die behördliche Einstellung der „Pädagogischen Blätter“ 1936* Schulpolitik, Presserecht und Verwaltungsgerichtsbarkeit in der Zeit des Autoritären Ständestaates
}

\section{Zur Entwicklung der Schul- politik in Österreich bis 1933}

„[D]as Schulwesen aber ist, und bleibet allzeit ein Politikum", lautet einer der vielleicht bekanntesten Aussprüche Maria Theresias. ${ }^{1}$ Aus dem Zusammenhang gerissen und mit einem modernen Verständnis des Wortes „Politikum“ versehen, findet der Satz auch heute noch oft Verwendung, und zwar meist dann, wenn es darum geht, zu betonen, dass die Gestaltung von Schulorganisation und Schulunterricht leider nicht nur vom aktuellen Stand der erziehungswissenschaftlichen Forschung abhängt, sondern auch wesentlich von der jeweils herrschenden politischen Ideologie geprägt ist. Im Jahre 1770, als Maria Theresia den Ausspruch tätigte, hatte er allerdings eine andere Bedeutung, und den Anlass hatte die Ernennung eines Schulmeisters in Wolfsberg in Kärnten gegeben, was nicht - wie bis dahin üblich - durch den katholischen Pfarrer des Ortes, sondern durch eine staatliche Behörde erfolgt war, wogegen der Bischof von Lavant Beschwerde erhoben hatte. ${ }^{2}$ Mit dem zitierten Satz begründete Maria

\footnotetext{
* Meinem Vater, dem Erziehungswissenschafter emer. o. Univ.-Prof. Dr.phil. Dr.h.c. Richard OLECHOWSKI, zum 75. Geburtstag gewidmet.

${ }^{1}$ HfD v. 13. 10. 1770 MThGS VI, 1224.

2 ENGELbRECHT, Bildungswesen III, 98.
}

Theresia die Abweisung der Beschwerde. Gemeint war also, dass es sich beim Schulwesen um eine staatlich-weltliche Angelegenheit, nicht um eine Angelegenheit der Kirche handelte.

$\mathrm{Zu}$ Recht werden die theresianischen Reformen als der Beginn eines staatlichen Schulwesens in Österreich angesehen, doch muss hinzugefügt werden, dass dies keineswegs auch das Ende der kirchlich geführten Schule bedeutete. Vielmehr wurde die von der Kirche seit Jahrhunderten fast monopolartig gepflegte Materie auch weiterhin von dieser reklamiert, und die Monarchie war weder willens noch fähig, das Schulwesen komplett $\mathrm{zu}$ übernehmen, vielmehr traten Kirche und Staat in ein Verhältnis der Kooperation, das freilich von Zeit zu Zeit verschieden und mal mehr, mal weniger harmonisch gestaltet war. Welch hohe Bedeutung der Kirche aber noch in dem von uns hier darzustellenden Zeitraum zukam, sei mit folgenden, wenigen Zahlen illustriert: ${ }^{3}$ Von den 168 allgemeinbildenden Sekundarschulen, die im Schuljahr 1936/37 das Öffentlichkeitsrecht besaßen, wurden 86 vom Bund, 45 von der katholischen Kirche betrieben; von den 4.065 Männern und Frauen, die sich zu jener Zeit auf den Lehrberuf vorbereiteten, besuchten 2.221 eine kirchliche Lehrerbildungsan-

\footnotetext{
${ }^{3}$ Nach ENGELBRECHT, Bildungswesen V, 301.
} 
stalt und lediglich 1.844 eine entsprechende Bundesanstalt.

Die enge Verflochtenheit von Staat und Kirche ging aber noch weit über das bloß Organisatorische hinaus, sie zeigte sich auch in den Lehrplänen und im Alltag des Schulunterrichts. Selbst das auf dem Höhepunkt des Liberalismus in Österreich entstandene Staatsgrundgesetz über die allgemeinen Rechte der Staatsbürger von 1867 hatte in seinem Artikel 14 zwar Glaubensund Gewissensfreiheit verheißen und auch bestimmt, dass „niemand [...] zu einer kirchlichen Handlung oder zur Theilnahme an einer kirchlichen Feierlichkeit gezwungen werden" könne, doch gleich darauf die Ausnahme gemacht: „in sofern er nicht der nach dem Gesetze hiezu berechtigten Gewalt eines Anderen untersteht." Gemeint waren damit nicht zuletzt die Schülerinnen und Schüler, für die das Morgengebet und die Teilnahme am Schulgottesdienst auch nach 1867 noch Pflicht war und bei denen eine Nichtteilnahme an den religiösen Übungen disziplinär geahndet wurde. ${ }^{5}$ Andere, die Macht der katholischen Kirche im Schulbereich weiter absichernde Gesetzesbestimmungen fanden sich auch für die Lehrenden, so etwa die Bestimmung, dass zum Schulleiter nur bestellt werden könne, der die Befähigung zum Religionsunterricht jener Konfession habe, der die Mehrzahl der Schüler angehört, ${ }^{6}$ was de facto für Juden und Protestanten einen weitgehenden, für Konfessionslose einen völligen Ausschluss vom Direktorenamt bedeutete.

Das Jahr 1918 brachte hier einen zweifachen Einbruch, und zwar zum einen durch die Beseitigung der monarchischen Staatsform und der damit verbundenen Absage an jede Art religiös

\footnotetext{
${ }^{4}$ Art. 14 Abs. 2 StGG-ARStB.

${ }^{5}$ Vgl. insbes. die $\S \S 10,63,74$ und 191 der Schul- und Unterrichtsordnung v. 29. 9. 1905, Z. 13.200, Verordnungsblatt für den Dienstbereich des Ministeriums für Kultus und Unterricht (Wien 1905) Nr. 49.

${ }^{6}$ Gesetz v. 2. 5. 1883, RGBl. 53.
}

legitimierter staatlicher Herrschaft, zum anderen durch den Umstand, dass in der neu gegründeten Republik wichtige Schulämter an die Sozialdemokraten gingen, wie insbesondere an den vormaligen Volksschullehrer und sozialdemokratischen Reichsratsabgeordneten Otto Glöckel, der am 5. November 1918 zum Unterstaatssekretär der deutschösterreichischen Staatsregierung ernannt wurde und am 15. März 1919 das Unterrichtswesen als Ressort zugeteilt bekam. In den etwa eineinhalb Jahren seiner Amtstätigkeit setzte er eine Reihe von einschneidenden Reformen, von denen hier zunächst der Erlass vom 10. April 1919 hervorgehoben sein soll, mit dem Glöckel - unter ausdrücklicher Berufung auf das zuvor genannte Staatsgrundgesetz - den Zwang zur Teilnahme an religiösen Übungen für Schülerinnen und Schüler öffentlicher Schulen abschaffte ${ }^{7}$ und der "geradezu als der Kristallisationspunkt für das Verhältnis von Sozialdemokratischer Partei und Kirche in der Ersten Republik angesehen werden" kann. ${ }^{8}$ Dass dieser Erlass alsbald schlicht als der "GlöckelErlass" bezeichnet wurde, zeigt nicht zuletzt, wie sehr der Unterstaatssekretär mit dieser Maßnahme von seinen politischen Gegnern auch persönlich in Verbindung gebracht wurde und sich eine Reihe von Feinden schuf, die nicht ganz zu Unrecht - diesen Erlass nur als einen ersten Auftakt für eine Reihe weiterer antiklerikaler Maßnahmen sahen. ${ }^{9}$

Mit der Beschlussfassung über das Bundes-Verfassungsgesetz am 1. Oktober 1920 und dem Rücktritt der Staatsregierung am 22. Oktober endete die erste Phase von Glöckels politischer Tätigkeit für die junge Republik; die zweite Pha-

\footnotetext{
${ }^{7}$ Erlaß des d.ö. Unterstaatsekretärs für Unterricht vom 10. 4. 1919, Z 950/U betreffend die Teilnahme der Schuljugend an den religiösen Übungen, in: Volkserziehung. Amtliche Nachrichten des Deutschösterreichischen Unterrichtsamtes 1919, Nr. 9.

${ }^{8}$ R. OLECHOWSKI, Schulpolitik 591; vgl. auch DERS., Schul- und Bildungspolitik 100.

${ }^{9}$ ENGELbRECHT, Bildungswesen V, 89.
} 
se setzte am 28. März 1922 mit seiner Wahl zum Amtsführenden Präsidenten des Wiener Stadtschulrates ein. (Formeller Präsident dieser Behörde war ex lege der Bürgermeister.) Auf den Raum Wien beschränkt und vielfach nur in Form eines "Schulversuches", gelang es ihm, einige zentrale schulpolitische Vorstellungen der Sozialdemokratie durchzusetzen, und mit den 1927 beschlossenen Bundesgesetzen über die Hauptschule und über die Mittelschule fand zumindest ein Teil von Glöckels Reformvorstellungen Eingang auch in das Regelschulwesen. ${ }^{10}$ Von der ursprünglichen Maximalforderung nach einer gemeinsamen Schule für alle Zehn- bis Vierzehnjährigen, welche intern differenzieren und so auf die Einzigartigkeit jedes Kindes besser eingehen können sollte, musste letztlich Abstand genommen werden. Aber immerhin wurde mit der Hauptschule ein Schultyp geschaffen, der eine interne Aufteilung der Schüler in zwei „Klassenzüge“ als Regelfall vorsah. Anfangs als minder begabt eingestufte Schüler wurden in den zweiten Klassenzug aufgenommen, konnten sich später jedoch für den ersten Klassenzug qualifizieren, vom ersten Klassenzug wiederum war ein Wechsel ins Gymnasium theoretisch möglich; inwieweit dieses Ziel auch praktisch erreicht wurde, war regional unterschiedlich und wird auch in der Literatur durchaus unterschiedlich bewertet. ${ }^{11}$

Auf die übrigen Reformmaßnahmen Glöckels in seiner zwölfjährigen Amtszeit als Stadtschulratspräsident kann hier nicht im Einzelnen eingegangen werden. Viele von ihnen verwirklich-

${ }^{10}$ BG v. 2. 8. 1927, BGB1. 244 betreffend die Regelung des Mittelschulwesens (Mittelschulgesetz); BG v. 2. 8. 1927, BGBl. 245 womit einige Bestimmungen des Reichsvolkschulgesetzes ... abgeändert werden (Hauptschulgesetz). Vgl. dazu ACHS, Schulreform 229f.; DERS., Austromarxismus 284ff., R. OLECHOWSKI, Schulpolitik, 596f.; ENGELBRECHT, Bildungswesen V, 76ff.; NUSSBAUMER, Bildung 81f.

${ }^{11}$ ACHS, Schulreform 231f., R. OLECHOWSKI, Schulpolitik 599ff.; ENGELBRECHT, Bildungswesen V, 101. ten reformpädagogische Ansätze, wie etwa die „Pädagogik vom Kinde aus“: Der Lehrstoff sollte nicht nach abstrakten, wissenschaftstheoretischen Gesichtspunkten vorgetragen werden; vielmehr sollte sich das Kind gewisse fächerübergreifende "Lebensgebiete“ selbständig durch Schreiben, Zeichnen, Singen u.a. Tätigkeiten aktiv erarbeiten. Derartige Methoden waren international einzigartig, sodass zahlreiche internationale Wissenschafter nach Wien, dem damals so bezeichneten „Mekka der Pädagogik", kamen, um die neuen Schulstrukturen, Lehrpläne, Lehrbücher und die Maßnahmen zur Verbesserung der Lehrerausbildung kennen $\mathrm{zu}$ lernen. ${ }^{12}$

\section{Verfassungsbruch und Presserecht 1933/34}

Als 1861 im österreichischen Reichsrat die Beseitigung der neoabsolutistischen Zensur beraten und die Rückkehr zur Pressefreiheit beschlossen worden war, hatte der liberale Abgeordnete Eduard Herbst resümiert: „Wer dem Volke seine Freiheiten nimmt, wird gewiß zu allererst die Axt an die Preßfreiheit [legen] in der Ueberzeugung [...], daß mit der Preßfreiheit alle anderen wieder gewonnen werden können." 13

Zweiundsiebzig Jahre später sollte sich die Richtigkeit seiner Ansicht bestätigen: Denn in der für die österreichische Geschichte so entscheidenden Ministerratssitzung vom 7. März 1933 - der ersten nach dem Rücktritt der drei Nationalratspräsidenten am 4. März und nach Ausgang der deutschen Reichstagswahl vom 5. März - stand die Frage der Pressefreiheit im

\footnotetext{
12 ACHS, Schulreform 227; DERS., Politische Bildung 320f.; R. OLECHOWSKI, Schulpolitik 595; DACHS, Schule und Politik 55ff.; NusSBAUMER, Bildung 81. ${ }^{13}$ StPAH 1. Sess., 1958.
} 
Mittelpunkt der Beratungen. ${ }^{14} \mathrm{Zu}$ einem neuen, autoritären Kurs gedachte die Regierung überzugehen, und mithilfe einer Zensur sowie auch mit Beschränkungen der Versammlungsfreiheit wollte man die $\mathrm{zu}$ erwartende Opposition so ungefährlich wie möglich machen. Doch gab Justizminister Kurt Schuschnigg zu bedenken, dass „in Österreich alle Möglichkeiten einer Einengung des Presserechts durch die lex Ofner verfassungsmäßig so gut wie ausgeschlossen" seien.15 - Mit der "lex Ofner" war der am 30. Oktober 1918, unmittelbar nach Gründung der Republik auf Antrag des Abgeordneten Julius Ofner gefasste Beschluss der Provisorischen Nationalversammlung gemeint, ,jede Zensur“ aufzuheben und die zur Zeit des Ersten Weltkrieges beseitigte Pressefreiheit wiederherzustellen. ${ }^{16}$ Dieser Beschluss war 1920 auch Bestandteil der Bundesverfassung geworden; eine Umgehung erschien kaum möglich.

Bundeskanzler Engelbert Dollfuß aber hatte offenbar bereits seine Entscheidung getroffen, als er seinen Ministern erklärte, dass die genannten Maßnahmen auch zur „Wiederaufrichtung der heimischen Wirtschaft" notwendig seien: Es war dies eine direkte Anspielung auf das - bereits in den Jahren davor wiederholt verwendete - Kriegswirtschaftliche Ermächtigungsgesetz 1917 (KwEG), das die Erlassung von Notverordnungen ermöglichte, aber eben nur in diesem engen Rahmen: „zur Förderung und Wiederaufrichtung des wirtschaftlichen Lebens, zur Abwehr wirtschaftlicher Schädigungen und zur Versorgung der Bevölkerung mit Nahrungsmitteln und anderen Bedarfsge-

\footnotetext{
${ }_{14}$ Zum verfassungsgeschichtlichen Hintergrund vgl. statt vieler BERCHTOLD, Verfassungsgeschichte $697 \mathrm{ff}$. ${ }^{15}$ Ministerrat v. 7. 3. 1933, in: ENDERLE-BuRCEL, Protokolle des Ministerrates VIII/2, 393-395.

${ }^{16}$ Beschluss der Provisorischen Nationalversammlung v. 30.10. 1918 StGBl. 3; vgl. dazu TH. OleCHOWSKI, Preßrecht 665ff.
}

genständen.“17 Auf diese Weise presse- und versammlungsrechtliche Maßnahmen zu rechtfertigen, war zwar äußerst fadenscheinig; doch wurde bereits in dieser Ministerratssitzung deutlich, dass es der Regierung nicht um Legalität, sondern nur um den Schein der Legalität ankam, und dafür reichte das KwEG offenbar aus. Man einigte sich schließlich auf eine Verordnung, die nach Aussage des Justizministers "eine Art von Vorzensur" enthalte, "die aber nach außen hin als solche nicht in Erscheinung treten dürfe, weil verfassungsmäßig jede Zensur ausgeschlossen sei." ${ }^{18}$

Anknüpfungspunkt der Verordnung vom 7. März $1933^{19}$ war das sog. Pflichtstück, das nach dem Pressegesetz von 1922 von jeder Zeitung und von jedem Druckwerk bis zu drei Druckbögen ( $=48$ Seiten) sowohl bei der Staatsanwaltschaft als auch bei der Sicherheitsbehörde hinterlegt werden musste, sobald mit der Verbreitung begonnen wurde.20 Entscheidend war das Moment der Gleichzeitigkeit: Verzögerte sich die Hinterlegung nur um wenige Minuten, stellte dies eine Übertretung dar, die mit bis zu 250 Schillingen geahndet werden konnte. ${ }^{21} \mathrm{Um}$ gekehrt bewirkte jede Hinterlegung vor Beginn der Verbreitung, dass Polizei und Staatsanwaltschaft noch vor der Öffentlichkeit Kenntnis vom Inhalt der Druckschrift nehmen und gegen sie

\footnotetext{
${ }^{17}$ Kriegswirtschaftliches Ermächtigungsgesetz 24.7. 1917 RGBl. 307.

${ }^{18}$ Kurt Schuschnigg im Ministerrat v. 7.3.1933, in: ENDERLe-BurCel, Protokolle des Ministerrates VIII/2, 397.

${ }^{19}$ Verordnung der Bundesregierung v. 7.3.1993, BGBl. 41 betreffend besondere Maßnahmen zur Hintanhaltung der mit einer Störung der öffentlichen Ruhe, Ordnung und Sicherheit verbundenen Schädigungen des wirtschaftlichen Lebens.

${ }^{20} \S 20$ BG 7. 4. 1922, BGBl. 218 über die Presse. Die Pflichtstücke dürfen nicht mit den Freistücken verwechselt werden, auf die gewisse öffentliche Bibliotheken nach $\S 21$ Pressegesetz ein Bezugsrecht hatten. ${ }^{21} \S 22$ Pressegesetz 1922 in Verbindung mit dem BG 27. 7. 1926, BGBl. 192.
} 
einschreiten konnten - und das war definitionsgemäß Zensur. Tatsächlich hatte die Zensur zur Zeit des Neoabsolutismus (1852-1860) und zur Zeit des Ersten Weltkrieges (1914-1918) darauf beruht, dass man einfach den Zeitpunkt der Hinterlegung nach vorne verlegt hatte - und genauso verfuhr die Bundesregierung 1933: Zwar nicht alle Zeitungen, aber immerhin jene, bei denen ab Inkrafttreten der Verordnung zumindest einmal ein Gericht eine Beschlagnahme wegen einer gerichtlich strafbaren Handlung angeordnet oder bestätigt hatte, hatten das Pflichtstück bereits zwei Stunden vor Verbreitungsbeginn abzugeben - eine indirekte Drohung mit Zensur also, die aber ausreichte, dass die Zeitungen von sich aus Selbstzensur ausübten, wollten sie nicht die tatsächliche Verhängung einer Zensur riskieren! Auch ließ die Verordnung bezüglich der genannten inkriminierten Zeitungen eine weitere Institution aus den Zeiten der Monarchie wieder aufleben: das berüchtigte „objektive Verfahren“. Dieses verdankte seinen Namen nicht etwa seiner besonderen Objektivität, sondern dem Umstand, dass hier kein Subjekt, sondern ein Objekt, die Zeitung selbst, gleichsam auf der Anklagebank saß und die Richter allein aufgrund des Antrags des Staatsanwaltes über das Verbot des Druckwerkes entschieden. ${ }^{22}$ Somit kehrte die Verordnung vom 7. März 1933 vielfach zu „bewährten“ Mitteln der Pressekontrolle zurück, bereitete damit der Pressefreiheit, wie sie zur Zeit der Ersten Republik bestanden hatte, ein jähes Ende, und mutete doch im Vergleich zu den pressepolitischen Maßnahmen, die zur selben Zeit die Nationalsozialisten in Deutschland einleiteten, ${ }^{23}$ seltsam altmodisch an. ${ }^{24}$

\footnotetext{
22 TH. OleChOWSKI, Preßrecht 636ff.

${ }^{23}$ Mit Erlass des Reichspräsidenten vom 13.3. 1933, dRGB1. I S. 104 wurde nur eine Woche später in Berlin ein „Reichsministerium für Volksaufklärung und Propaganda" geschaffen, mit dessen Leitung Joseph Goebbels betraut wurde; vgl. Arbeiter-Zeitung Nr. 73
}

In der Folge wurde die Vorzensur über eine Reihe von Zeitungen verhängt, wobei jene über die „Arbeiter-Zeitung“ am 24. März naturgemäß den größten Widerstand und sogar einen allgemeinen Streik der Wiener Zeitungsdrucker hervorrief, der aber rasch beendet werden konnte. ${ }^{25}$ Eine gänzliche Unterdrückung von periodischen Druckschriften war jedoch nur dann möglich, wenn sie sich für eine verbotene Partei betätigten:26 Am 26. Mai war der Kommunistischen Partei, am 19. Juni auch der NSDAP jede Betätigung in Österreich verboten worden, und eine am 7. Juli ergangene Notverordnung verbot Druckereien bei Strafe des Konzessionsverlustes, sich für eine verbotene politische Partei zu betätigen, weshalb Blätter wie die „Rote Fahne“ oder die nationalsozialistische „Deutschösterreichische Tageszeitung“ ihr Erscheinen einstellen mussten. ${ }^{27}$ Als am 12. Februar 1934 der Bürgerkrieg ausbrach und die Bundesregierung mittels

v. 14. 3. 1933, 5. - Diese Ausgabe der Arbeiter-Zeitung war konfisziert worden, was Grundlage für das weitere preßrechtliche Vorgehen gegen diese Zeitung war; sie erschien am selben Tag mit „weißen Flecken“ v.a. im Leitartikel („Die Arbeiter sind bereit“) in zweiter Auflage.

${ }^{24}$ Vgl. zu dieser Parallelität auch DuchKOWITSCH, Zensur 565.

${ }^{25}$ Siehe dazu die eigene Berichterstattung der Arbeiter-Zeitung Nr. 84 v. 26.3.1933, 1, sowie auch die Sondernummer "Der Sozialdemokrat" mit einem Aufruf „An die arbeitende Bevölkerung Wiens!" Das Kleine Blatt Nr. 34 v. 26.3. 1933 berichtete auf seiner Titelseite über die Unterredung des Vizekanzlers mit den Streikvertretern; vgl. ferner Duchkowitsch, Zensur 566; PelinkA, Scheuch, 100 Jahre AZ 99. Unrichtig CsOKLICH, Presse 725, nach welchem der Streik bereits eine Reaktion auf die Verordnung vom 7. 3. 1933 gewesen wäre.

${ }^{26}$ So noch ein Erlass der Generaldirektion für die öffentliche Sicherheit vom 19. 11. 1934, vgl. MALINA, Bücherverbote 317.

${ }_{27}$ BGBl. 1933/200, 240 und 315. Vgl. dazu auch das Erk. des BGH 2. 1. 1935, BGHSlg. Nr. 176 A, wonach sich das Verbot auch auf ausländische kommunistische Parteien erstreckte und die Annahme von Druckaufträgen für diese ebenfalls mit Konzessionsverlust bestraft werden konnte. 
KwEG-Verordnung der Sozialdemokratischen Arbeiterpartei ,jede Betätigung in Österreich" verbot, ${ }^{28}$ bedeutete dies das Ende für die „Arbeiter-Zeitung“, die an jenem Montagmorgen zum letzten Mal erschien. Allerdings gelang es einem in die Tschechoslowakei geflohenen Teil der Redaktion schon am 25. Februar, also nicht einmal zwei Wochen später, die Arbeiter-Zeitung in Brünn [Brno] neu erscheinen zu lassen, und illegal gelangte sie von dort auch nach Österreich. ${ }^{29}$

Die am 1. Mai 1934 verkündete, neue Verfassung versprach in Artikel 26 jedem Bundesbürger das Recht der freien Meinungsäußerung „durch Wort, Schrift, Bild oder in sonstiger Weise“, fügte aber sogleich hinzu, dass „zur Verhütung von Verstößen gegen die öffentliche Ruhe, Ordnung und Sicherheit oder gegen die Strafgesetze eine vorgängige Prüfung der Presse", also eine Vorzensur, zulässig sei. ${ }^{30}$ - Viele Jahre zuvor hatte Hans Kelsen sich über das liberale Staatsgrundgesetz kritisch wie folgt geäußert: „Dadurch, daß Einschränkungen dieser Freiheit der Meinungsäußerungen durch einfaches Gesetz für möglich erklärt sind, ist seine staatsgrundgesetzliche Gewährleistung eigentlich in demselben Satze, in dem sie ausgesprochen wird, wieder aufgehoben. ${ }^{\text {" }} 1 \mathrm{Um}$ wie viel mehr hätte diese Kritik auf den Artikel 26 der Maiverfassung zugetroffen, der nichts mehr als eine leere Worthülse war, und der die rigorose Pressepolitik, wie sie nun schon seit über einem Jahr bestand, nicht im mindesten abmildern konnte.

\footnotetext{
${ }^{28}$ Verordnung der Bundesregierung v. 12. 2. 1934, BGBl. 78.

${ }^{29}$ CsOKLICH, Presse 725; PelinKa, SCHeuch, 100 Jahre AZ 104.

${ }^{30}$ Verfassung des Bundesstaates Österreich, BGBl. 1934 I/239 = II/1. Vgl. zur ständisch-autoritären Verfassungsordnung allgemein WOHNOUT, Regierungsdiktatur; TÁLOS, NEUGEBAUER, Austrofaschismus, jeweils mit weiteren Nachweisen.

${ }^{31}$ KelSEN, Staatsrecht 59; vgl. dazu schon TH. OleCHOWSKI, Grundrechte 35.
}

Allein, Hans Kelsen hatte Österreich schon vier Jahre zuvor verlassen. Sein Schüler Adolf Julius Merkl hingegen, seit 1932 Ordinarius für Staatsund Verwaltungsrecht an der Universität Wien, hatte 1935 ein Lehrbuch zum neuen Verfassungsrecht verfasst, in der er auch eingehend die Grundrechte dieser neuen Verfassung, „das grundsätzlich weitestgehende Zugeständnis an den politischen Zeitgeist des vergangenen [ $=$ des 19.] Jahrhunderts" besprach. In diesem Zusammenhang thematisierte er auch "das wissenschaftlich in jüngster Zeit klar erfaßte und gestellte Problem der Bedeutung von Gesetzesvorbehalten" in Grundrechten: Man müsse zwischen „verfassungsfesten“ und "biegsamen" Grundrechten unterscheiden, die letzte Gruppe könne „durch einfaches Gesetz entweder überhaupt oder in gewissen Beziehungen durchbrochen werden" und stelle daher nur eine Schranke für Justiz und Verwaltung dar. ${ }^{32}$ Die Meinungsäußerungsfreiheit aber, so musste Merk1 feststellen, sei in der Verfassung so sehr eingeschränkt worden, dass man zu ,jener Rechtslage“ zurückgekehrt sei, „wie sie bis 1848 bestanden hat" - womit Merkl das Wort Zensur vermied. „Ein derart beschränkbares Recht der Meinungsäußerung kann schwerlich als Grundrecht [...] gedeutet werden. [...] Wenn dem Gesetzgeber überhaupt keine Schranken gezogen werden sollten, so hätte es sich vielleicht im Hinblick auf die optische Wirkung empfohlen, des Rechtes der Meinungsäußerung in der Verfassung überhaupt nicht zu gedenken, denn auch im Falle des Schweigens der Verfassung über die Meinungsäußerung wären alle beabsichtigten Beschränkungen derselben dem Gesetzgeber freigestanden. ${ }^{\text {“33 }}$

Dies also war der verfassungsrechtliche Rahmen für jene presserechtliche Maßnahme, die im Zusammenhang mit den „Pädagogischen Blät-

\footnotetext{
32 MERKL, Verfassung 36.

${ }^{33}$ MerkL, Verfassung 47f. Vgl. dazu auch WoHnOut, Kanzlerdiktatur 968.
} 
tern" die größte Bedeutung haben sollte und daher hier auch noch anzuführen ist: Das Bundesgesetz vom 26. Oktober 1934 betreffend die Herausgabe von Zeitungen. ${ }^{34}$ Dieses Gesetz führte eine Konzessionspflicht für alle zumindest einmal monatlich erscheinenden Zeitungen, Zeitschriften und Zeitungskorrespondenzen ein. Bereits bestehende Periodika hatten binnen zwei Wochen ab Inkrafttreten des Gesetzes, d.h. bis zum 22. November, um eine solche Konzession („Bewilligung“) anzusuchen. Die Bewilligung war insbesondere dann zu entziehen, wenn dies aus Gründen der öffentlichen Ruhe, Ordnung und Sittlichkeit geboten erschien, und sie konnte auch entzogen werden, wenn der Herausgeber die ihm gegebenen Bedingungen und Auflagen nicht einhielt.

\section{Die „Pädagogischen Blätter"}

$\mathrm{Zu}$ den ersten schulpolitischen Maßnahmen der Regierung Dollfuß nach Beseitigung des parlamentarischen Systems gehörte die Aufhebung des "Glöckel-Erlasses“.35 Dass für diese Maßnahme der 10. April 1933, somit der 14. Jahrestag des Erlasses, gewählt worden war, zeugt von

\footnotetext{
${ }^{34}$ G 26. 10. 1934, BGB1. 340; dieses Gesetz war nicht von dem von der Maiverfassung zur Gesetzgebung berufenen Bundestag, sondern von der Bundesregierung auf Grundlage des sog. Ermächtigungsgesetzes 1934 (BVG 30.4. 1934, BGBl. I 255) beschlossen worden. Die Beschlussfassung erfolgte auf Antrag des für das Sicherheitswesens zuständigen Staatssekretärs Hans Hammerstein-Equord ohne Debatte: ENDERLEBurCEL Protokolle des Ministerrates IX/1, 491f. Es ist nicht möglich, hier auf sämtliche weitere preßrechtliche Maßnahmen der Jahre 1933/34 einzugehen; eine Übersicht bietet MEISTER, Zusammenstellung; vgl. auch MALINA, Bücherverbote 314ff.; DUCHKOWITSCH, Zensur 567.

${ }^{35}$ Erlaß des Ministers für Unterricht vom 10. 4. 1933, Z 10098, in: Verordnungsblatt für den Dienstbereich des Bundesministeriums für Unterricht Nr. 25. Vgl. ENGELBRECHT, Bildungswesen V, 264; DACHS, Schule und Politik 227; NussBAUMER, Bildung 85.
}

der Symbolträchtigkeit dieses Aktes. Er war nur der Auftakt zu einer Reihe von Maßnahmen, mit denen die schulpolitischen Veränderungen der letzten Jahre rückgängig gemacht werden sollten. Die ideologische Richtung gab dabei ab 1934 die Maiverfassung vor, welche dem Staat die Aufgabe zuwies, „darüber zu wachen, daß die Kinder religiös-sittlich erzogen und ihnen die Grundlagen des Wissens vermittelt werden, die für ihre Heranbildung zu tüchtigen Menschen und guten Bürgern erforderlich sind" (Artikel 31 Absatz 6). Die Betonung des Religiösen und die Erweckung einer „vaterländischen Gesinnung“ war denn auch das Ziel vieler schulpolitischer Maßnahmen, wie sie etwa bei der Novellierung des Haupt- und des Mittelschulgesetzes zum Tragen kamen. Ein weiterer Effekt dieser Novellen war, dass ein Wechsel vom einen in den anderen Schultyp deutlich schwieriger geworden war. ${ }^{36}$

Bedeutsamer aber noch als die Maßnahmen im Bereich von Schulorganisation und Schulunterricht war die Personalpolitik des autoritären Regimes, die sich bereits in den ersten Monaten der Diktatur deutlich machte, ${ }^{37}$ nach Niederschlagung des Februaraufstandes 1934 und Verbot der Sozialdemokratischen Partei und ihrer Vorfeldorganisationen aber geradezu verhee-

\footnotetext{
${ }^{36}$ Verordnungen v. 23.3. 1934, BGBl. 197 und 198; beispielhaft für die zeitgenössische Literatur, die die neuen Werte $\mathrm{zu}$ vermitteln suchte, sei statt vieler genannt: SIMONIC, Heimat und Vaterland 496-504. Vgl. zu dieser Thematik näher FISCHL, Schulreform 72; R. OleCHOWSKI, Schulpolitik 603; ENGELBRECHT, Bildungswesen V, 280ff.; DACHS, Schule und Politik 229f., 261f.; ACHS, Politische Bildung 323.

${ }^{37}$ Besonders schwerwiegend war die Tendenz, verheiratete Lehrerinnen "abzubauen": Verordnungen 17. 1. 1934, BGBl. 36 und 29. 1. 1934, BGBl. 58 (Salzburg); Verordnung 19.3.1934, BGBl. 170 (Burgenland); Verordnung 23. 3. 1934, BGBl. 178 (Oberösterreich). Ferner wurde starker Druck gemacht, dass möglichst alle Lehrer der Vaterländischen Front beitreten: Siehe dazu etwa den Erlass des Ministers für Unterricht 8. 1. 1934, Z 466, in Verordnungsblatt Nr. 6. Vgl. auch ENGELBRECHT, Bildungswesen V, $265 f f$.
} 
rende Folgen hatte. Nachdem bereits am 12. Februar mit Bürgermeister Karl Seitz der nominelle Präsident des Wiener Stadtschulrates verhaftet worden war, folgte am nächsten Tag die Verhaftung des Amtsführenden Präsidenten Glöckel in seinen Amtsräumen. ${ }^{38}$ Zum Bundeskommissär für Wien wurde Richard Schmitz bestellt, der später auch formell als Bürgermeister und Präsident des Stadtschulrates nachfolgte, während Prof. HR Robert Krasser, der dem Stadtschulrat schon zuvor als Mitglied angehört hatte, die Amtsführung desselben übernahm. Eine "Säuberungswelle" folgte, bei der 102 von 500 Schulleitern ihre Funktion verloren. ${ }^{39}$ Nach Inkrafttreten der Maiverfassung wurde dann versucht, die Lehrerschaft ständisch zu strukturieren und eine „Kameradschaft der öffentlichen Lehrpersonen“ zu schaffen. ${ }^{40}$ Die bisherigen Gewerkschaften wurden aufgelöst, an ihre Stelle trat der "Gewerkschaftsbund der österreichischen Arbeiter und Angestellten“. Aufgelöst wurden im Februar 1934 ferner viele sozialdemokratische Vereine wie u.a. der „Zentralverein der Wiener Lehrerschaft" ${ }^{\text {" } 41}$ oder der Verein „Freie Schule - Kinderfreunde. “ ${ }^{42}$

Der Zentralverein der Wiener Lehrerschaft war 1896 von einer Gruppe sozialdemokratischer

\footnotetext{
${ }^{38}$ FISCHL, Schulreform 72; ENGELBRECHT, Bildungswesen V, 266; DACHS, Schule und Politik 259.

${ }^{39}$ DACHS, Austrofaschismus und Schule 286.

${ }^{40}$ BG 19. 10. 1934, BGBl. II 294 über die Einrichtung des Berufsstandes der öffentlichen Bediensteten; das Gesetz ist auszugsweise abgedruckt in den Pädagogischen Blättern 1 (1934) Heft 5, 71-75. Vgl. dazu auch ENGELBRECHT, Bildungswesen V, 267; DERS, Lehrervereine 91

${ }^{41}$ Dazu SALFENAUER, Zentralverein.

${ }^{42}$ Bescheid der Generaldirektion für die öffentliche Sicherheit 13. 2. 1934, Zl. 120136 - GD2, auszugsweise abgedruckt bei WEISS, Das rote Schönbrunn 96. Zur Beschlagnahme und Liquidation des Vermögens dieses Vereines siehe den 2002 von Heinz Weiss angelegten Akt im Archiv des Vereins für Geschichte der Arbeiterbewegung, Sacharchiv, Lade 6, Mappe 14. Ebendort auch die Broschüre von WINTER, 10 Jahre.
}

Lehrer um Karl Seitz gegründet worden und stand in enger personeller und inhaltlicher nicht immer auch rechtlicher ${ }^{43}$ - Verbindung mit der 1895 gegründeten Zeitschrift „Freie Lehrerstimme“. Diese zuletzt von der Freien Lehrergewerkschaft Österreichs herausgegebene Fachzeitschrift hatte schon im Mai 1933 gegen die Aufhebung des Glöckel-Erlasses protestiert ${ }^{44}$ und die Regierungspolitik in den folgenden Nummern immer schärfer kritisiert, das JuniHeft sprach sogar bereits von einer „klerikofaschistischen Diktatur", die "letzten Endes an dem Widerstand des österreichischen Volkes scheitern" werde, worauf dieses Heft beschlagnahmt und der verantwortliche Redakteur, Karl Scheidner, wegen "Aufwiegelung (§300 StG)" angeklagt wurde. ${ }^{45}$

Der 1905 gegründete Verein „Freie Schule“ war ursprünglich parteiübergreifend organisiert worden, fusionierte aber 1923 mit dem wesentlich größeren, sozialdemokratischen Verein „Kinderfreunde", der - neben vielen anderen Aktivitäten ${ }^{46}$ - eine reiche Publikationstätigkeit entfaltete und 1924 sogar einen eigenen Verlag, den "Jungbrunnen“, ins Leben rief. Theoretisches Organ der "Kinderfreunde“ war ab 1921 die "Sozialistische Erziehung“; für Mädchen und Buben erschien monatlich das „Kinderland“, dem ein „Mitteilungsblatt" für die Erwachsenen beigefügt war. ${ }^{47}$ Das "Kinderland“ brachte Bildergeschichten, Rätsel und Erzählungen, aber vermittelte auch politische Bildung für

\footnotetext{
${ }^{43}$ Die Eigentumsverhältnisse der Freien Lehrerstimme veränderten sich häufig, vgl. dazu auch REITER, Harpner 238.

${ }^{44}$ Freie Lehrerstimme XXXIX (1933), Folge 5, 1.

${ }^{45}$ Freie Lehrerstimme XXXIX (1933), Folge 6, 1; Folge 7, 4f. Vgl. zur Situation der sozialdemokratischen Lehrerzeitschriften 1933/34 auch DACHS, Schule und Politik 245.

${ }^{46}$ So die Errichtung eines Kinderheimes in Schloss Schönbrunn, vgl. dazu ausführlich WEISS, Das rote Schönbrunn.

${ }^{47}$ WEISS, Das rote Schönbrunn 79f. Vgl. allgemein auch UITZ, Die österreichischen Kinderfreunde.
} 
Kinder. So wurden z.B. im April-Heft 1933 die Fragen: „Was geschieht in Deutschland? Wer ist Hitler?" mit einfachen, klaren Worten beantwortet. ${ }^{48}$ Das Juni-Heft 1933 ging auf direkte Konfrontation mit dem Dollfuß-Regime: Gleich die erste Seite brachte den Text des Volksliedes "Die Gedanken sind frei“ mit dem erläuternden Zusatz: ,jetzt oft zu singen“; es folgte die Aufforderung: „Fragt eure Eltern, was es bedeutet, daß unser Parlament nicht zusammen treten kann", und schließlich eine Bilderfolge, die die Geschichte der Arbeiteremanzipation veranschaulichte..$^{49}$ Letztere war es, die die Behörde veranlasste einzuschreiten, und am 12. Mai wurde das Juni-Heft beschlagnahmt. ${ }^{50}$

Damit fielen sowohl die "Freie Lehrerstimme“ als auch das "Kinderland“ unter jene Zeitschriften, die nach der Verordnung vom 7. März einer Vorzensur unterworfen waren. $\mathrm{Zu}$ weiteren presserechtlichen Maßnahmen kam es jedoch in beiden Fällen nicht mehr, da, wie erwähnt, jene Vereine, die als Eigentümer und Herausgeber fungierten, im Februar 1934 aufgelöst wurden. Ein Wechsel in der Herausgeberschaft, auch unter leicht verändertem Titel, wäre der Sicherheitsbehörde nach §19 Pressegesetz anzuzeigen und faktisch so gut wie unmöglich gewesen. Beide Zeitschriften mussten daher im Februar 1934 ihr Erscheinen einstellen. ${ }^{51}$

Drei Monate später, wenige Tage nach Veröffentlichung der Maiverfassung, erschien jedoch in der Druckerei Rödinger in Wien XIV. eine völlig neue Monatszeitschrift: „Pädagogische

\footnotetext{
${ }^{48}$ Kinderland, 14. Jahrgang, April 1933, 36.

${ }^{49}$ Kinderland, 14. Jahrgang, Juni 1933 (erste Auflage), 61, 64, 66-67.

${ }^{50}$ Nach erfolgter Beschlagnahme wurde eine zweite Auflage herausgebracht, diese enthielt auf Seite 66 anstelle der ersten Seite der Bildergeschichte auszugsweise einen Abdruck des Gerichtsbeschlusses vom 12.5. 1933. Unrichtig daher WeISS, Das rote Schönbrunn 95, der angibt, der Abdruck sei erst im Juli-Heft erfolgt.

${ }^{51}$ Vgl. dazu auch DACHS, Schule und Politik 298.
}

Blätter. Monatshefte für Erziehung und Unter-

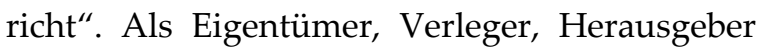
und verantwortlicher Schriftleiter wurde ein "Josef Enslein, Bürgerschuldirektor i.R.“ angegeben.

Enslein war in Pädagogenkreisen kein Unbekannter: Am 8. März 1870 in Wien geboren und in einem Waisenhaus aufgewachsen, war er in St. Pölten gemeinsam mit dem nur ein Jahr älteren Seitz zum Lehrer ausgebildet worden. Danach unterrichtete er als Unterlehrer an verschiedenen Wiener Schulen und wurde so auch ein enger Weggefährte Glöckels. In der Sozialdemokratischen Arbeiterpartei selbst hatte Enslein niemals eine Funktion ausgeübt, doch war er sowohl 1896 an der Gründung des Zentralvereins der Wiener Lehrerschaft, als auch 1905 an der Gründung des Vereins "Freie Schule“ beteiligt gewesen. 1920 übernahm Enslein die Leitung der vom Verein „Freie Schule“ gegründeten Schule im VIII. Wiener Gemeindebezirk in der Albertgasse 23,52 was juristisch problematisch schien, da er aus der Kirche ausgetreten war. Da Enslein die Ausbildung zum Religionslehrer absolviert hatte, erfüllte er die oben genannten, formellen Qualifikationserfordernisse zum Direktor; als er jedoch 1926, nach 36 Dienstjahren, auf eigenem Wunsch in den Ruhestand trat, wurde ihm aus dem genannten Grund die Zuerkennung des Titels "Schulrat" verweigert.53 Dem Stadtschulrat, in den er 1922 gewählt wurde, gehörte er noch nach seinem Eintritt in den Ruhestand bis 1934 an. Im Zentralverein hatte er von 1916-20 und wieder von 1928 bis zu dessen Auflösung 1934 die Funktion des Obmannes inne.

Dass der mittlerweile immerhin schon 64-jährige Enslein ausgerechnet in dieser Zeit eine neue Zeitschrift gründete, mochte auf dem ersten Blick überraschen. Andererseits war er einer der

\footnotetext{
52 STIMMER, Arbeiter von Wien, 159

${ }^{53}$ ENSLEIN, Schulrat.
} 
wenigen sozialdemokratischen Schulmänner, die bis dahin persönlich unbehelligt geblieben waren. ${ }^{54}$ Das nur sechzehn Seiten starke Heft im Oktavformat war ausgesprochen unscheinbar; das äußere Erscheinungsbild (insbesondere der Kopf der Zeitschrift mit dem Schriftzug „Pädagogische Blätter" in einer Schreibschrift) erinnerte zwar stark an die „Mitteilungen“ des aufgelösten Vereines „Freie Schule - Kinderfreunde $^{\text {" }}, 55$ doch wurde mit keinem Wort eine der aufgelösten Organisationen oder eingestellten Medien erwähnt. Enslein selbst hatte weder bei den "Mitteilungen“ noch bei der „Freien Lehrerstimme" als Herausgeber oder verantwortlicher Redakteur mitgewirkt, auch die Druckereien waren verschieden. Anstelle eines Editorials enthielt die erste, mit Mai 1934 datierte Nummer den Aufruf: „Alle Kolleginnen und Kollegen, die Wert legen auf wahrheitsgetreue Berichterstattung und objektive Stellungnahme $\mathrm{zu}$ wichtigen Angelegenheiten der Erziehung und des Unterrichts, werden zum Bezuge dieser Blätter und zur Mitarbeit herzlich eingeladen. Bezugspreis für 1934: 3 Schilling. ${ }^{\circ 56}$ Es folgte ein - sehr allgemein gehaltener - Aufsatz von Hofrat Leopold Scheuch ${ }^{57}$ über "Dauerwerte der Schulreform", ein unkommentierter Abdruck der für das Schulwesen bedeutsamen Bestimmungen der Verfassung und des zugleich mit der Verfassung verkündeten Konkordates, ferner Personalnachrichten, ein didaktischer Beitrag zum Sprachunterricht von Klementine

\footnotetext{
541899 war Enslein in einem Strafverfahren wegen "Gutheißung einer ungesetzlichen Handlung" (im konkreten Fall: einer Wahlrechtsdemonstration) angeklagt, aber freigesprochen worden; vgl. dazu REITER, Harpner 291f.

${ }^{55}$ Einige Exemplare dieser „Mitteilungen“ befinden sich im Archiv des Vereins für Geschichte der Arbeiterbewegung, Sacharchiv, Lade 6, Mappe 14 B.

${ }^{56}$ Pädagogische Blätter 1 (1934) Heft 1, 1.

${ }^{57}$ Der pensionierte niederösterreichische Landesschulrat war ein enger Weggefährte Glöckels gewesen; vgl. zu ihm KUCHER, Vorgeschichte 181.
}

Enslein, ${ }^{58}$ sowie die Ankündigung für ein Lehrer-Erholungsheim und die Bekanntmachung, dass man auch Rechtsauskünfte erteilen werde, sofern eine schriftliche Anfrage gestellt werde und „eine mit Anschrift und Marke versehene Briefhülle beiliegt.“ Mochte auch eine derartige Aufforderung zumindest zu denken geben - für die Behörden bot sich nicht der geringste Anhaltspunkt, das Erscheinen dieser neuen Zeitschrift zu verhindern.

Die Blattlinie setzte sich in den folgenden Nummern fort: Im zweiten Heft (Juni 1934) veröffentlichte Regierungsrat Theodor Steiskal, Bezirksschulinspektor i.R., einen Aufsatz über „Erziehung zu bewußter Heimatliebe“, der mit den Worten endete: „Das österreichische Volk kann sich verlassen: Die österreichische Lehrerschaft wird nicht erlahmen in der Erziehung der österreichischen Jugend $\mathrm{zu}$ bewußter Vaterlandsliebe - im Sinne zeitgemäßer Pädagogik. " 59 Die KwEG-Verordnung, mit der das Hauptschulgesetz novelliert worden war, wurde in Form eines synoptischen Vergleichs mit der Stammfassung abgedruckt und lediglich kommentiert durch den unveränderten Abdruck einer Rede von Kurt Schuschnigg, der in der Zwischenzeit neben dem Justiz- auch das Unterrichtsministerium übernommen hatte. Als das erwähnte Bundesgesetz vom 26. Oktober 1934 über die Konzessionspflichtigkeit von Zeitschriften in Kraft trat, wird Enslein verpflichtet gewesen sein, um eine Konzession nachzureichen. Offenbar ${ }^{60}$ gab es keine Beanstandungen, und

\footnotetext{
${ }^{58}$ Klementine Enslein, geb. Haerdtl, war Lehrerin in der Albertgasse gewesen, wo sie ihren späteren Gatten Josef Enslein kennen gelernt hatte; vgl. Freie Lehrerstimme 70 (1965) Heft 3, 2-3: „Zu Josef Ensleins 95. Geburtstag am 8. März".

${ }^{59}$ Pädagogische Blätter 1 (1934) Heft 2, 19f. - Vgl. zu dem am 11. 7. 1945 verstorbenen Steiskal den Nachruf in der Freien Lehrerstimme 51 (1945) Heft 1, 5.

${ }^{60}$ Die pressepolizeilichen Akten zu den „Pädagogischen Blättern" befinden sich nicht im Österreichischen Staatsarchiv (ÖStA), sondern nach Angaben
} 
die Zeitschrift durfte weiter erscheinen, was angesichts der bisher dort erschienenen Beiträge auch nicht verwunderlich war.

Doch schon das Dezemberheft 1934 enthielt einen Aufruf "An unsere Leser“: „Wir wollen Stellung nehmen zu den zeitlichen Fragen der Schulreform, wie zu den ewigen Problemen der Menschheitserziehung. Diese Arbeit ist wohl der beste Dienst am Volke, ist Heimatdienst und Menschheitsdienst zugleich!" 61 Und im zweiten Erscheinungsjahr, 1935, wurde der Ton allmählich schärfer.

So berichtete die Mai-Ausgabe 1935, dass die Leitungen der "Lehrer-Kameradschaften“, der gesetzlichen Standesvertretung der Lehrinnen und Lehrer, in den einzelnen Ländern und in Wien noch nicht bestellt seien, und vermutete, dass noch keine Einigung zwischen den „verschiedenen Meinungs-Richtungen (politische Parteien gibt es bekanntlich nicht mehr)" zustande gekommen sei.62 Die Juni-Ausgabe wurde direkter und beklagte die Langsamkeit des berufsständischen Aufbaues; die seinerzeit von Glöckel „ins Leben gerufene Lehrerkammer“ habe sich wesentlich schneller konstituieren können. ${ }^{63}$

Etwas näher eingegangen werden soll auf jenen Artikel im September/Oktober-Heft 1935, in dem ein richtungsweisendes Erkenntnis des österreichischen Bundesgerichtshofes (BGH) besprochen und kritisiert wurde. Dieser Gerichtshof war mit der Maiverfassung 1934 sozusagen an die Stelle von Verfassungs- und Verwaltungsgerichtshof zugleich getreten, wobei die meisten ehemaligen verfassungsgerichtli-

dieses Archivs noch immer in der Bundespolizeidirektion Wien. Eine entsprechende Anfrage daselbst führte jedoch leider $\mathrm{zu}$ einem negativen Ergebnis: Antwortschreiben der Bundespolizeidirektion Wien 25. 5. 2010, P 7/186397/1/2010.

${ }^{61}$ Pädagogische Blätter 1 (1934) Heft 5, 65.

62 Pädagogische Blätter 2 (1935) Heft 5, 75.

63 Pädagogische Blätter 2 (1935) Heft 6, 91. chen Kompetenzen - nicht jedoch die verfassungsgerichtliche Bescheidprüfung! - von einem besonderen Verfassungssenat wahrgenommen wurden, dem außer vier Berufsrichtern auch vier außerordentliche, politisch bestellte Richter angehörten. Die Berufsrichter stammten großteils aus dem Personalstand des ehemaligen Verwaltungsgerichtshofes, doch war die Neukonstituierung 1934 für eine politische „Säuberung“ benutzt worden. Der BGH sah sich selbst in der Tradition vor allem des ehemaligen Verwaltungsgerichtshofes, und als er 1935 ein religionsrechtliches Erkenntnis von grundsätzlicher Bedeutung schöpfen wollte, zu dem bereits ein Judikat des Verwaltungsgerichtshofes vorlag, wollte er nur mit einem „Verstärkten Senat" mit sieben Richtern davon abgehen. ${ }^{64}$ Konkret ging es dabei um die (vermeintliche?) Spitzfindigkeit, ob ein „Religionsaustritt“ als „Übertritt" zu qualifizieren sei. Wenn nämlich Eltern von einer gesetzlich anerkannten Religion zu einer anderen übertraten, so nahmen die unter sieben Jahre alten Kinder die neue Religion ihrer Eltern an. Wenn die Eltern jedoch aus der Kirche austraten, ohne einer anderen beizutreten, so hatten nach Ansicht des BGH die Kinder in der Kirche zu verbleiben, da ja nur ein Austritt, kein Übertritt erfolgt sei. ${ }^{65}$ In den „Pädagogischen Blättern" wurde diese Entscheidung von Wilhelm Börner vom pädagogischen und ethischen Standpunkt aus scharf kritisiert: Konfession dürfe nicht mit Religion verwechselt werden. Von der Entscheidung des BGH seien Atheisten und Pantheisten ebenso betroffen wie Angehö-

\footnotetext{
${ }^{64}$ Es war dies eine 1934 in die Verwaltungsgerichtsbarkeit eingeführte Neuerung, die eine entsprechende Einrichtung beim Obersten Gerichtshof zum Vorbild hatte und auch 1945 beim wieder errichteten Verwaltungsgerichtshof beibehalten wurde. Vgl. dazu TH. OLECHOWSKI, Bundesgerichtshof 92f.; allgemein zum Bundesgerichtshof auch MERKL, Verfassung 114.

${ }^{65}$ BGH 21. 6. 1935 BGHSlg 552 A; vgl. zu diesem Erkenntnis bereits TH. OLECHOWSKI, Bundesgerichtshof 97ff.
} 
rige von gesetzlich nicht anerkannten Religionsgemeinschaften.

Am 23. Juli 1935 starb Otto Glöckel, worüber die „Pädagogischen Blätter“ in ihrer nächstfolgenden Nummer ausführlich berichteten. Als unmittelbare Todesursache wurde eine „Herzlähmung" angegeben, aber der eigentliche Grund für Glöckels Ableben, nämlich, dass die sechsmonatige Haft in Wöllersdorf den 60-jährigen gebrochen hatte, auch nicht verschwiegen: „Nach seiner im Oktober [1934] erfolgten Freilassung aus Gefängnis und Spital lebte er in voller Zurückgezogenheit. [...] das arme physische Herz [konnte] nicht aushalten [...], was die letzte Zeit seines Lebens über ihn gebracht hatte. "66 Glöckel, „der beste Freund der Lehrer, der warmherzige Anwalt der Kinder, der große Reformator der österreichischen Schule", wurde ausführlich gewürdigt, die „Blütezeit der österreichischen Schule" unter Glöckel gepriesen. „Aus allen Teilen der Erde pilgerten Erzieher und Lehrer nach Wien, voll der Bewunderung für ein Werk, das [...] Freude in die Kinderherzen, in die Arbeit der Schule" gebracht hatte. ${ }^{67}$ Das Dezemberheft 1935 brachte eine weitere Würdigung Glöckels, und während der erste Nachruf anonym erschienen war, zeichnete nunmehr Steiskal verantwortlich. ${ }^{68}$ Ausführlich würdigte er "das reiche pädagogische Denken und Schaffen im Zeitraum 1919-1934", die „neue methodische Einstellung der Lehrerschaft im Unterrichts-und Erziehungsverfahren" sowie die Berücksichtigung der „Ergebnisse der Wissenschaft" bei Glöckels Reformen und bezeichnete den Verstorbenen als „Schöpfer der österreichischen Heimatschule."

Dieser Aufsatz sollte im späteren Verlauf noch mehrmals von den Behörden zitiert werden, doch wird Stadtschulratspräsident Robert Krasser wohl schon zuvor beschlossen haben, recht-

\footnotetext{
${ }^{66}$ Pädagogische Blätter 2 (1935) Heft 8, 112.

${ }^{67}$ Pädagogische Blätter 2 (1935) Heft 8, $111 f$.

${ }^{68}$ STEISKAL, Otto Glöckel.
}

lich gegen die „Pädagogischen Blätter" vorzugehen. Bereits am 2. Dezember 1935 richtete der Stadtschulrat eine "Note“ an die Bundespolizeidirektion Wien, und diese erließ am 31. Dezember einen Bescheid, mit dem Enslein nach §5 Absatz ${ }^{69}$ des Gesetzes vom 26. Oktober 1934 die Bewilligung zur weiteren Herausgabe der „Pädagogischen Blätter“ entzogen wurde. ${ }^{70}$ Enslein erhob gegen diesen Bescheid Berufung bei der - damals organisatorisch beim Bundeskanzleramt angesiedelten Generaldirektion für die öffentliche Sicherheit, die jedoch mit Bescheid vom 16. Februar 1936 den erstinstanzlichen Bescheid bestätigte. Mit Zustellung am 25. Februar erwuchs dieser letztinstanzliche Bescheid in Rechtskraft; bereits das Februarheft der „Pädagogischen Blätter“ konnte nicht mehr erscheinen.

Enslein beschloss jedoch, alle rechtlichen Möglichkeiten auszuschöpfen: Am 2. April 1936 reichte er, vertreten durch seinen Rechtsanwalt Dr. Oswald Richter, Beschwerde beim BGH ein, und zwar "wegen Verletzung der verfassungsgesetzlich gewährleisteten Rechte nach Art. 26 [Verfassung 1934] und des Rechtes auf Gesetzmäßigkeit der Verwaltung. - Die Erlassung des Bescheides der Polizeidirektion erfolgte nicht gesetzmässig im Sinne des $\S 56$ AVG. "71 Die zitierte Bestimmung des Allgemeinen Verwaltungsverfahrensgesetzes (AVG) ${ }^{72}$ ordnete an, dass der Erlassung eines Bescheides eine Feststellung des maßgeblichen Sachverhaltes vorangehen müsse, was nach Ansicht des Beschwerdeführers unterblieben war, es wurden also Mängel im Verwaltungsverfahren vorgebracht.

\footnotetext{
${ }^{69} \mathrm{Im}$ Bescheid wurde irrtümlich Absatz 3 genannt, was von der Berufungsbehörde richtiggestellt wurde.

${ }^{70}$ Zur Quellenlage vgl. schon oben Anm. 60. Die nachfolgenden Ausführungen stützen sich großteils auf den verwaltungsgerichtlichen Akt im AdR, BGH A 577/36.

${ }^{71}$ AdR, BGH A 577/36/1, 2.

${ }^{72}$ BG 21. 7. 1925, BGBl. 274 über das allgemeine Verwaltungsverfahren.
} 
Das - ausführlich begründete - Vorbringen Ensleins war somit teils Verfassungs-, teils Gesetzesbeschwerde. Organisatorisch war dies für den BGH kein Problem, da Verletzungen von verfassungsrechtlich gewährleisteten Rechten nicht anders als Verletzungen von sonstigen Rechten behandelt wurden; sie fielen nicht in die Kompetenz des Verfassungssenates sondern in die des für die Materie auch sonst zuständigen Senates - somit ausgerechnet in die Kompetenz des Senates 10, der das oben genannte religionsrechtliche Erkenntnis geschöpft hatte, das in den „Pädagogischen Blättern“ kritisiert worden war. Referent war nach der Geschäftsordnung HR Karl Lintner. Er leitete das Verfahren nach $\S 47$ Bundesgerichtshofgesetz ${ }^{73}$ ein und übermittelte dementsprechend der Generaldirektion für öffentliche Sicherheit im Bundeskanzleramt ein Exemplar der Beschwerdeschrift, verbunden mit der Aufforderung, eine Gegenschrift zu erstatten und die Akten des Verwaltungsverfahrens vorzulegen. ${ }^{74}$

\section{Der vereinsrechtliche Aspekt}

Zwölf Jahre nach diesen Ereignissen, im Jahre 1948, verfasste Enslein eine kurze autobiographische Skizze, in der er die „Pädagogischen Blätter" bemerkenswerter Weise nicht erwähnte. Dagegen berichtete er, dass er in der Zeit nach Verbot des "Zentralvereins" einen „kleinen Kreis treuer Freunde" um sich geschart hatte, mit dem er das Vereinsleben fortsetzte. „Die Namen wechselten, die Menschen aber waren stets die gleichen: Pädagogischer Verein ,Paul Natorp', Lehrersektion der Bergsteigervereinigung, Pädagogische Auskunftsstelle des Reichsvereines der Hausfrauen Österreichs (Rohö), Bücherei im Café Filmhof, Sprachkurse

\footnotetext{
${ }^{73}$ BG 12. 7. 1934, BGBl. II 123 über die Einrichtung und das Verfahren des Bundesgerichtshofes.

${ }^{74}$ AdR, BGH A 577/36/1, letzte (nicht paginierte) Seite.
}

im Café Landtmann, Dienstagnachmittage im Café Jungwirth u.a. “75

Der erwähnte Verein „Paul Natorp“ (benannt nach dem neukantianischen Philosophen und Pädagogen, 1854-1924) soll angeblich schon 1933 „in Ahnung kommender Ereignisse“ gegründet worden sein; von den „über 3000 Mitgliedern des Zentralvereins fanden aber nur mehr 250 den Mut, zu dieser neuen Organisation überzuwechseln. ${ }{ }{ }^{6}$ Im November 1934 taucht der Verein erstmals auch in den „Pädagogischen Blätter" auf; es wird angekündigt, dass Klementine Enslein im Vortragssaal des Vereins (VI. Bezirk, Dreihufeisgasse 1) eine „Vortragsreihe über methodische Fragen im Rechen- und Sprachunterricht" abhalten wolle. ${ }^{77}$ Auch in den nachfolgenden Blättern wurde regelmäßig über Tätigkeiten des Vereins berichtet. ${ }^{78}$ Parallel dazu hatte der Verein jedoch damit begonnen, auch ein eigenes Mitteilungsblatt herauszugeben, dessen erste Nummer im Oktober 1935 erschien und „Blätter für Pädagogik“ hieß. Nicht nur vom Titel, sondern auch vom äußeren Erscheinungsbild bis hin zum Namenszug des Titels im Kopf glich diese Zeitschrift auffallend den „Pädagogischen Blättern“, um-

${ }^{75}$ ENSLEIN, Schulrat 4. Vgl. demgegenüber die Darstellung von ENGELBRECHT, Lehrervereine 98, der das Wirken illegaler sozialdemokratischer Lehrerorganisationen als sehr gering einschätzt, sich bei seiner Untersuchung allerdings auf den Sekundarbereich, in dem die Sozialdemokratie wesentlich schwächer vertreten war, konzentriert.

${ }^{76}$ SALFENAUER, Zentralverein 155. Leider entbehrt diese Arbeit weitgehend näherer Quellenangaben, sodass eine Verifizierung schwer möglich ist. Nach STIMMER, Arbeiter von Wien 161, hatte der Verein „mehr als 150 Mitglieder".

77 Pädagogische Blätter 1 (1934) Heft 4, 64.

78 Pädagogische Blätter 2 (1935) Heft 1, 16; Heft 2, 30 u. 32; Heft 3, 48; Heft 4, 64; Heft 5, 80; Heft 6, 96; Heft 8, 124; Heft 9, 139; Heft 10, 169; Pädagogische Blätter 3 (1936) Heft 1, 22. Wie ENGELBRECHT, Lehrervereine 100, betont, war das Ausschreiben von Vorträgen auch eine Reaktion auf die weitgehenden Beschränkungen der Versammlungsfreiheit seit 1933. 
fasste aber im Gegensatz zu diesen nur vier Seiten und wurde vom Verein selbst alle zwei Monate herausgegeben; der Vereinsobmann, Schulrat Franz Ritter, fungierte als verantwortlicher Redakteur. Als die „Pädagogischen Blätter“ ihr Erscheinen einstellen mussten, traten die „Blätter für Pädagogik" nahtlos an ihre Stelle: Das Februar-Heft 1936 wuchs auf 36 Seiten und enthielt nunmehr außer Vereinsnachrichten auch fachdidaktische Aufsätze (zu Rechenunterricht, Naturkunde etc) sowie Hinweise zu Schulbüchern; der Inhalt blieb vollkommen unpolitisch. Dazu kam, dass die "Blätter für Pädagogik“ aufgrund ihrer bloß zweimonatlichen Erscheinungsweise nicht unter den Anwendungsbereich des Gesetzes vom 26. Oktober 1934 fielen, also von keiner Konzession abhängig waren. Presserechtlich war diesem neuen Organ nicht beizukommen.

Am 20. April 1936 beschloss jedoch der Lehrerverein "Paul Natorp" seine Selbstauflösung, womit auch die „Blätter für Pädagogik“ ihr Erscheinen einstellen mussten. ${ }^{79}$ Angeblich war „die Aufnahme von klerikalen Lehrern in den Vorstand" verlangt worden, was der Verein verweigert hatte, womit nur die Auflösung übrig blieb. ${ }^{80}$ Allerdings beantragte Enslein unmittelbar darauf bei der Vereinsbehörde die Ge-

${ }^{79}$ Die Vereinsauflösung wurde in der Wiener Zeitung Nr.111, 22.4.1936, 17, bekannt gegeben. Am 22. 8. 1937 richtete die Generaldirektion der Nationalbibliothek an den ehemaligen Vereinsvorsitzenden die Aufforderung, Freistücke nach § 21 Pressegesetz 1922 abzuliefern, worauf dieser mit Schreiben vom 12. 9.1937 von der erfolgten Vereinsauflösung berichtete und dass die „Blätter für Pädagogik“ aus diesem Grund nicht mehr erscheinen. Dieser handschriftlich verfasste Brief ist mit den in der Nationalbibliothek befindlichen Exemplaren des Jahres 1936 (Signatur 646007-B Neu Per) zusammen gebunden.

80 SALFENAUER, Zentralverein 156. Möglicherweise hing das Ansinnen der "Aufnahme von klerikalen Lehrern“ mit der zur selben Zeit erfolgten Umgestaltung des Katholischen Schulvereins zusammen, über den die Wiener Zeitung Nr. 111, 22. 4. 1936, 4, berichtete. nehmigung zur Gründung eines neuen Vereins, der diesmal nach dem slawischen Schulreformer Johann Amos Comenius (Jan Ámos Komenský, 1592-167081) benannt sein sollte. Dieser Antrag wurde mit Bescheid des Sicherheitsdirektors für Wien vom 28. April abschlägig beschieden. In der Begründung hieß es u.a., dass Enslein „führender Politiker der sozialdemokratischen Partei gewesen" sei, und dass die von ihm herausgegebenen „Pädagogischen Blätter" „kritisch negativistische und aufwieglerische Stellen in jeder Nummer enthalten" hätten. Aus der Person des Proponenten wäre daher $\mathrm{zu}$ besorgen, dass es sich beim „Pädagogenklub Comenius" um einen Verein handle, der Bestrebungen der verbotenen sozialdemokratischen Partei fördern wolle. Enslein erhob gegen diesen Bescheid Beschwerde, die jedoch mit Bescheid des Bundeskanzleramtes vom 15. Juli 1936 abgewiesen wurde. Daraufhin erhob Enslein auch gegen diesen Bescheid Beschwerde beim BGH. Wieder landete die Beschwerde beim Senat 10, und Hofrat Lintner musste erneut die Generaldirektion für die öffentliche Sicherheit ersuchen, eine Gegenschrift zu erstatten und die Akten vorzulegen. Damit waren nunmehr zwei parallele Verfahren streitanhängig.

\section{Die Verfahren vor dem Bundesgerichtshof}

Am 7. Mai 1936 übermittelte das Bundeskanzleramt dem BGH die Akten des presserechtlichen Verfahrens. Im Begleitschreiben gab man sich gelassen. Weder Akteneinsicht noch eine mündliche Verhandlung wurden beantragt, ja sogar von einer Gegenschrift wollte der Abteilungsleiter, Ministerialrat Dr. Walter Pfeifer, „im Hinblick auf die erschöpfende Begründung des

\footnotetext{
${ }^{81}$ Vgl. zu ihm R. OleCHOWSKI, Comenius.
} 
h.o. Bescheides und den vollkommen geklärten Sachverhalt" Abstand nehmen. ${ }^{82}$

Das war Wasser auf die Mühlen des Beschwerdeführers, hatte er doch in seiner Beschwerdeschrift ausführlich dargelegt, dass schon im ganzen bisherigen Verfahren der Sachverhalt nicht ordnungsgemäß festgestellt worden war: Aus der Tatsache alleine, dass eine Zeitung in pädagogischen Fragen Positionen beziehe, die sich mit jenen der "bestandenen sozialdemokratischen Partei“ decken, könne nicht schon auf ein Naheverhältnis der Zeitung zur Partei geschlossen werden, zumal diese Grundsätze auch von anderen Parteien vertreten wurden. „Dass der Herausgeber Sozialdemokrat war, vermag natürlich für die Beweisführung des angefochtenen Bescheides überhaupt nichts zu ergeben." Gleiches gelte für die Mitarbeiter. „Was die Schreibweise anbelangt, so bestreitet der Beschwerdeführer nachdrücklich, dass die Zeitschrift im sozialdemokratischen Sinne geführt wurde“, gab aber gleichzeitig zu bedenken, dass die Partei nicht wegen ihrer Meinung in kulturellen Dingen verboten worden sei, sondern „weil sie nach dem Erkennen der zuständigen Behörden für eine Aufstandsbewegung verantwortlich war" ${ }^{\prime \prime}{ }^{83}$ Sei es jetzt auch unzulässig, etwa Pazifismus oder den Kampf gegen Alkohol zu betreiben, wie es die Partei getan habe?

Die Beschwerde nahm auch konkret zu einigen im Bescheid gerügten Zeitschriftenaufsätzen Stellung: Wenn in diesen z.B. kritisiert worden sei, dass die Lehrerkameradschaft noch immer nicht konstituiert sei, könne man darin ja nur ein „Verlangen nach endgültiger Konstituierung eben dieser Einrichtungen" erblicken; der Nachruf auf Otto Glöckel sei vollkommen unpolitisch gewesen, angesichts der Bedeutung Glöckels habe sogar die (christlichsoziale) "Reichspost"

\footnotetext{
${ }^{82}$ AdR, BGH A 577/36/2.

${ }^{83}$ AdR, BGH A 577/36/1, 6.
}

einen Nachruf verfassen müssen. ${ }^{84}$ Und auch der Kommentar zum BGH-Erkenntnis über den Konfessionswechsel sei kein Werben für Konfessionslosigkeit: Wenn darin gefordert werde, dass Kinder bis zum 14. Lebensjahr ,jede Religionsänderung der Eltern mitmachen" sollen, dann bedeute dies ja auch umgekehrt, dass konfessionslose Eltern, die eine Konfession annehmen, auch ihre Kinder in diese Glaubensgemeinschaft mitnehmen!85 Dies alles hätte die Behörde in einem gesetzlich geregelten Ermittlungsverfahren klären müssen; Enslein bezweifelte, dass ein solches jemals stattgefunden habe. Wenn es aber stattgefunden habe, so seien ihm dessen Ergebnisse bis dato unbekannt und er habe keine Gelegenheit gehabt, sich zu den Erhebungsresultaten zu äußern.

Enslein verlangte daher die Durchführung einer mündlichen Verhandlung vor dem BGH, welche - nach einmaliger Verschiebung86 - am 21. Dezember auch tatsächlich stattfand. Der Senat wurde vom Präsidenten des BGH, Dr. Ernst Durig, persönlich geleitet; außer dem Referenten Lintner gehörten ihm auch noch die Hofräte Dr. Vitus Schmidt, Dr. Rudolf Lennkh und Dr. Alois Körner an. Zur Verhandlung erschienen der Rechtsanwalt des Beschwerdeführers, Dr. Oswald Richter und als Vertreter der belangten Behörde Sektionsrat Dr. Richard Kreis. ${ }^{87}$

\footnotetext{
${ }^{84}$ Reichspost Nr. 202, 24. 7. 1935, 3. Vgl. ebendort auf Seite 1 den anonym verfassten Artikel über „Die Mittelschulerneuerung in Oesterreich", der die schulpolitischen Ziele der Regierung erläuterte. Dass beide Artikel in derselben Nummer erschienen, war sicher kein Zufall.

${ }^{85}$ AdR, BGH A 577/36/1, 7-9.

${ }^{86}$ Zunächst, am 12. 11. 1936, war der 17. 12. als Verhandlungstag beschlossen worden; am 30.11. wurde die Vertagung auf den 21. 12. verfügt. Die Gründe für die Vertagung gehen aus dem Akt nicht hervor.

${ }^{87}$ Niederschrift über die Verhandlung am 21. 12. 1936, AdR, BGH A 577/36/1. - Mit Ausnahme Lintners hatten alle genannten Richter auch schon im Vorjahr dem Senat 10, der das oben erwähnte Erkenntnis
} 
Rechtsanwalt Richter brachte in seinem mündlichen Vortrag im Wesentlichen die gleichen Argumente wie in seiner Beschwerdeschrift, führte aber noch weiter aus, dass die Note des Stadtschulrates noch 40 Stellen der Zeitschrift beanständet habe, der Bescheid jedoch „nur mehr 3 oder 4" - deren Haltlosigkeit er näher darlegte. Von polizeilicher Seite habe es niemals eine Verwarnung oder eine Beschlagnahme der „Pädagogischen Blätter“ gegeben, weshalb das Verbot völlig überraschend gekommen sei. - Sektionsrat Kreis hob hervor, dass seine Behörde verpflichtet sei einzuschreiten, wenn der Inhalt einer Zeitschrift ,auch nur mittelbar eine Anlehnung an die Ideologie" der Sozialdemokratischen Partei darstelle. „Auf dem Gebiet der Pädagogik lasse sich eine Grenzlinie zwischen politischer und kultureller Betätigung nicht ziehen. Der sozialdemokratischen Partei sei auf pädagogischem Gebiete mit Recht vorgeworfen worden, dass sie die Jugend in ungenügendem Masse zur Achtung der Autorität erzogen habe, ja geradezu zu deren Missachtung erzogen habe, aus welcher Haltung dann die Revolution erwachse. Jede politische Partei habe ihre bestimmten Grundsätze, solche habe auch die sozialdemokratische Partei gehabt, diese seien aber für den heutigen Staat untragbar; das gelte auch für die vorliegende Zeitschrift. Und, gerichtet gegen den Vorwurf, keine Erhebungen gepflogen zu haben, meinte Kreis, dass es sich hier geradezu um „ein Schulbeispiel für die Entbehrlichkeit von Erhebungen" handle. Denn was müsse noch erhoben werden, wenn die Artikel vorliegen und deren Qualifizierung Aufgabe der Behörde sei? - Nach etwa 45minütiger Verhandlung zog sich der Senat zurück und erklärte, dass er das Erkenntnis zu einem späteren Zeitpunkt schriftlich bekannt geben werde.

BGHSlg. 552 A geschöpft hatte, angehört; vgl. TH. OLECHOWSKI, Bundesgerichtshof 94.
In der Zwischenzeit, am 30. November, hatte Ministerialrat Dr. Pfeifer aber auch die Akten zum zweiten anhängigen Verfahren, jenem gegen den „Pädagogenklub Comenius“, vorgelegt, und im Gegensatz zum vorherigen Verfahren hatte er es für nötig befunden, eine ausführliche Gegenschrift zu verfassen: Enslein wurde darin ,als führender sozialdemokratischer Schulmann" bezeichnet, was für sich schon ausreiche, um einen „Missbrauch“ zu befürchten, zumal die Zweckbestimmungen des Vereins in seinen Statuten ganz allgemein und unbestimmt umschrieben seien (es hieß dort u.a., dass der „Pädagogenklub Comenius" zum Ziel habe, „pädagogische Kenntnisse zu vermitteln und zu vertiefen", und zwar durch die "Veranstaltung von Versammlungen und Vorträgen, die Errichtung einer Vereinsbibliothek und die Herausgabe von Druckschriften“88). Es sei aber „Sache des Proponenten, die Zweckbestimmungen der Satzungen so zu fassen, dass Zweifel über die politische Richtung der zu entfaltenden Vereinstätigkeit nicht entstehen können." 89 Dies war eine Umkehr der Beweislast! Nicht die Behörde hatte nachzuweisen, dass Enslein staatsgefährdende Absichten hatte, sondern Enslein hatte nachzuweisen, dass er keine derartigen Absichten hatte! Er stand also sozusagen unter Generalverdacht. Deutlich wird, dass der Rechtsstaat, wiewohl der äußere Anschein noch weiter gewahrt wurde, in Wirklichkeit schon längst verlassen worden war. Und der nachfolgende Bericht Enslein passt gut in dieses Bild:

„Am 18. Jänner 1937 wurden wir [gemeint: die Gruppe um Enslein, die weiterhin - illegale Zusammenkünfte abhielt] bei einer Vorbesprechung $\mathrm{zu}$ einer Studienreise nach Paris und London infolge einer Denunziation verhaftet und zwanzig von uns mußten mit mir eine Wo-

\footnotetext{
${ }^{88}$ Zitiert nach der Gegenschrift des BKA v. 30.11. 1936 im bundesgerichtlichen Verfahren, AdR, BGH, A 2136/36.

${ }^{89}$ Gegenschrift des BKA v. 30. 11. 1936 (wie Anm. 88).
} 
che auf der Elisabethpromenade [dem Polizeigefangenenhaus im IX. Bezirk] zubringen." Akten sind auch zu diesem Vorfall nicht auffindbar, ${ }^{91}$ aber offenbar blieb die Begebenheit zumindest für Enslein ohne weitere Folgen. Fraglich bleibt somit der Zweck der Verhaftung. Wollte man Enslein einschüchtern, damit er seine Beschwerden zurückziehe? Sollte dies die Hoffnung der Polizei gewesen sein, so wurde sie enttäuscht. Beide Verfahren wurden bis zum Ende durchgeführt.

Vier Tage nach Ensleins Enthaftung, am 29. Jänner 1937, kam der Senat 10 in nichtöffentlicher Sitzung zusammen, um einen Beschluss im presserechtlichen Verfahren $\mathrm{zu}$ fassen. Der Referent, Hofrat Lintner, hatte einen Entwurf für das zu schöpfende Erkenntnis mitgebracht und stellte den Antrag, die Beschwerde abzuweisen: Was zunächst die behauptete Verletzung von Artikel 26 der Verfassung 1934 betreffe, so sei das Recht der freien Meinungsäußerung nur „innerhalb der gesetzlichen Schranken eingeräumt". Der angefochtene Bescheid stütze sich aber auf das Bundesgesetz über die Herausgabe von Zeitungen und könne daher nur dann verfassungswidrig sein, wenn auch das Bundesgesetz verfassungswidrig sei - letzteres sei aber nicht einmal vom Beschwerdeführer behauptet worden. Aber auch eine Verletzung einfachgesetzlich gewährleisteter Rechte liege nicht vor: Wenn das Gesetz der sozialdemokratischen Partei „jede Betätigung“ verbiete, dann gefährde ,jedes Geschehen, das solche Betätigung zu begünstigen geeignet ist [...] die Aufrechthaltung der Rechtsordnung" und müsse die Behörde einschreiten. Die Feststellungen der Behörde stünden im Einklange mit den Akten, die allein zu prüfen der BGH befugt sei, und seien auch schlüssig. Schließlich wurde auch der Vorwurf

\footnotetext{
${ }^{90}$ ENSLEIN, Schulrat 4.

${ }^{91}$ Die Verhaftung wird auch erwähnt bei STIMMER, Arbeiter von Wien 161; ENDERLE-Burcel u.a. Protokolle des Kabinettsrates 1, Anhang, 432.
}

des mangelhaften Verfahrens damit abgetan, dass es ein „Recht auf Gesetzmässigkeit der Verwaltung" nicht gebe. Überdies habe durchaus ein Verfahren nach § 56 AVG stattgefunden; „denn es wurden nicht nur sämtliche Stücke der in Betracht kommenden Zeitschrift beigeschafft, sondern auch noch Erhebungen über die Personen des Herausgebers und der Mitarbeiter der Zeitschrift gepflogen. Ueberdies wurde im Verfahren auch eine Aeusserung des Stadtschulrates von Wien verwertet."

Bedenken gegen diesen Antrag kamen von Hofrat Schmidt, der bemerkte, „dass eigentlich nie ein konkreter Artikel der Zeitschrift beanständet worden" sei und man nicht auf bloße Gefahr hin eine Bewilligung zur Herausgabe entziehen könne. Lintner, Lennkh und Körner hingegen betonten, dass es hier - anders als bei einer Beschlagnahme - nicht auf einen konkreten "Tatbestand" ankomme, sondern auf den "Zweck", die „Tendenz" bzw. das „Gesamtbild“ der Zeitschrift. Und hier sei allerdings der Eindruck entstanden, dass „Gedankengut, das die sozialdemokratische Partei gepflegt hat, weitergepflanzt" hatte werden sollen. - Präsident Durig schloss sich dieser Meinung an. Zwar sei es richtig, dass viele der in der Zeitschrift vertretenen Ansichten, ja auch „die von Glöckel vertretenen Grundsätze“, nicht nur von der sozialdemokratischen Partei vertreten worden waren; aber auch er habe den Eindruck gewonnen, dass die „Lobpreisung“ der „Glöckelschule" vor allem deshalb erfolgt sei, um „die sozialdemokratische Partei, die hinter dieser Schulbewegung stand, zu loben und die jetzige Schule als rückständig hinzustellen. Der Fall sei jedenfalls ein Grenzfall. “92

Bei der Abstimmung stimmten vier Stimmführer für den Referentenentwurf, lediglich

\footnotetext{
${ }^{92}$ Niederschrift über die Beratung am 29.01 1937, AdR, BGH A 577/36.
} 
Schmidt dagegen. Die Beschwerde Ensleins wurde abgewiesen.

Am 24. Februar 1937 kam dann auch das zweite Verfahren zur mündlichen Verhandlung. Die belangte Behörde, das Bundeskanzleramt, war in dieser Verhandlung nicht vertreten - ein Versehen oder nahm sie das Verfahren nicht mehr ernst? Der Vertreter des Beschwerdeführers, Rechtsanwalt Dr. Richter, war erschienen und wies in seinem Plädoyer darauf hin, dass man aus der Person des Proponenten keineswegs auf die Staatsgefährlichkeit eines Vereins schließen könne. Er verneinte auch, dass in Österreich nur eine einzige Weltanschauung zulässig sei. „Immer wieder sei von der Staatsführung jede Totalität in dieser Hinsicht abgelehnt worden. ... Man werde nicht die Aufführung von Lessings ,Nathan der Weise' verbieten, weil in diesem Werk Islam und Judentum dem Christentum irgendwie ethisch gleichgestellt werden, man verbiete ja auch nicht die Schriften des Comenius und Pestalozzi, die der Richtung des [Beschwerdeführers] nahestehen und die auch irgendwie von den derzeit in Oesterreich herrschenden Ideen abweichen. ${ }^{\text {"93 }}$

Die Beratung des Senates 10 fand noch am selben Tage statt. Wieder war es Schmidt, der als einziger für Enslein eintrat: „Es sei misslich zu sagen, jemand, der einmal einer nun verbotenen Richtung angehört hat, sei für alle Ewigkeit als staatsgefährlich anzusehen." Lennkh dagegen verwies auf die Entscheidung im Fall der „Pädagogischen Blätter": Man könne nicht einmal so, einmal anders entscheiden. „Der Antrag des Berichters auf Abweisung wird schliesslich mit einigen vom Vorsitzenden angeregten Aenderungen in der Fassung der Begründung einhellig angenommen. ${ }^{\prime 94}$ Auch die zweite Beschwerde Ensleins wurde somit als unbegründet abgewiesen.

\footnotetext{
${ }^{93}$ Mündliche Verhandlung vom 24. 2. 1937, AdR, BGH A 2136/36.

${ }^{94}$ Beratung vom 24. 2. 1937, AdR, BGH A 2136/36.
}

Die geradezu unglaubliche Willkür des BGH in diesem zweiten Verfahren wiegt umso schwerer, als er noch im November 1935 in einem ganz ähnlichen Fall judiziert hatte, dass die Tatsache alleine, dass ein Verein sowie auch dessen Leitung hauptsächlich aus ehemaligen NSDAPMitgliedern bestehe, die Auflösung des Vereins nicht rechtfertige. ${ }^{95}$ Die in Brünn erscheinende "Arbeiter-Zeitung" berichtete sowohl über das BGH-Verfahren zum „Pädagogenklubs Comenius" als auch über das zum "Naziverein" und kam zum Schluss: „Es gibt eben selbst beim Obersten Gericht zweierlei Maß für Rot und Braun - mit derselben Begründung wird den Nazi erlaubt, was Sozialisten verboten wird. ${ }^{\prime 96}$

Natürlich ist es spekulativ zu fragen, was wohl passiert wäre, hätte der BGH wenigstens einer der beiden Beschwerden Ensleins recht gegeben. Interessant aber mag immerhin sein, was die „Arbeiter-Zeitung“ im Mai 1936 unter der spöttischen Überschrift „Österreich ist ein Rechtsstaat" geschrieben hatte: Demnach hatte der BGH am 10. März 1936 eine Verfügung der Bundesregierung aufgehoben, mit der ein Eisenbahnerverein wegen sozialdemokratischer Betätigung verboten worden war. „Damit war der aufgelöste Verein natürlich wiederhergestellt. Hierauf hat die Regierung am 14. März alle Mitglieder des Vorstandes des Vereines ihrer Funktionen enthoben und einen Verwaltungsausschuss, der die Geschäfte zu führen habe, ernannt." "97 Auf diese Weise umging die Bundesregierung das höchstgerichtliche Erkenntnis, und es ist zumindest nicht undenk-

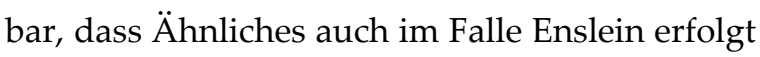
wäre.

\footnotetext{
95 BGH 29. 11. 1935, BGHSlg. 709 A.

${ }^{96}$ Arbeiter-Zeitung Nr. 6, 17. 3. 1937, 4f.: „Auch beim Bundesgerichtshof - zweierlei Maß für Rot und Braun".

${ }^{97}$ Arbeiter-Zeitung Nr. 7, 13. 5. 1936, 12. Das Erkenntnis konnte in der amtlichen Sammlung nicht gefunden werden.
} 


\section{Bilanz}

Über das Wesen des autoritären Regimes, welches 1934-1938 in Österreich an der Macht war, besteht auch mehr als siebzig Jahre später noch keine Einigkeit in der Literatur. ${ }^{98}$ Diese ist vielmehr bis zum heutigen Tag von ideologischen Auseinandersetzungen geprägt; und wenn ein Autor/eine Autorin das Regime als "austrofaschistisch" bezeichnet oder aber sich weigert, diesen Terminus zu verwenden, sagt dies mehr über ihn/sie als über das Regime aus. Einer sachlichen Diskussion, an der es noch vielfach mangelt, müssen vertiefte Untersuchungen vorangehen, die die Differenzen zwischen Ideologie und Praxis, zwischen Selbstdarstellung und Fremddarstellung des Regimes deutlich machen. ${ }^{99}$ Die hier dargestellten Verfahren, die zeigen, wie es um die Pressefreiheit in einer ideologisch so sensiblen Materie wie der Schulpolitik bestellt war, vermögen wenigstens einen kleinen Beitrag dazu zu liefern. In diesem Sinne seien folgende Feststellungen gemacht:

\footnotetext{
${ }^{98}$ Aus der Fülle der einschlägigen Literatur sei auf das Standardwerk von TÁlOS, NEUGEBAUER, Austrofaschismus hingewiesen, welches mit seinem Titel bereits eine Deutung der Epoche abgibt; aus der Literatur mit gegenteiliger Meinung auf WOHNOUT, Regierungsdiktatur; vgl. auch jüngst RUMPLER, Ständestaat ohne Stände.

${ }^{99}$ Berits 1980 stand die politische Justiz der Jahre 1933-1955 im Mittelpunkt eines Symposions, dessen Referate im Sammelband Justiz und Zeitgeschichte (Bd. I, 273-424) abgedruckt sind; eine Auseinandersetzung mit der Justiz des Bundesgerichtshofes unterblieb bei dieser Gelegenheit leider, ebenso bei HoltmanN, Autoritätsprinzip. Derzeit wird am Institut für Rechts- und Verfassungsgeschichte der Universität Wien unter Leitung von Prof. Ilse ReiterZatloukal ein Forschungsprojekt zu politisch motiviertem Vermögensentzug in Wien 1933-1938 durchgeführt [http://vermoegensentzug.univie.ac.at]; gemeinsam mit Oliver Rathkolb organisierte ReiterZatloukal vom 21.-26. 012011 ein interdisziplinäres Symposium „Österreich 1933-1938“ an der Universität Wien, dessen Ergebnisse ebenfalls veröffentlicht werden sollen.
}

1. Die Verheißung der Pressefreiheit in der Verfassung 1934 war rechtlich bedeutungslos. So wie schon $\mathrm{zu}$ Zeiten des Staatsgrundgesetzes, ging die Pressefreiheit nicht weiter, als dies von den einfachen Gesetzen vorgegeben war; im Unterschied zum Staatsgrundgesetz aber war nach Artikel 26 Verfassung 1934 sogar eine Vorzensur ausdrücklich gestattet. Das Presserecht jener Zeit vermittelt insgesamt auffallende Ähnlichkeiten mit dem der Ära des Neoabsolutismus, einer der dunkelsten Periode der österreichischen Pressegeschichte.

2. Das Schulwesen der Ersten Republik, welches insbesondere 1927 unter Mitwirkung beider großer Parteien im Sinne moderner pädagogischer Grundsätze reformiert worden war, wurde bereits unmittelbar nach Übergang zum autoritären Kurs ideologisch neu ausgerichtet, womit bereits Kinder zu einer Bejahung des diktatorischen Regimes erzogen wurden.

3. Die Verschmelzung von Verfassungs- und Verwaltungsgerichtsbarkeit in einem einzigen Gerichtshof hatte weit über das Organisationsrecht hinaus gehende Konsequenzen. Da der Rechtsschutz in Grundrechtsangelegenheiten nicht dem Verfassungssenat vorbehalten, sondern den ordentlichen Verwaltungsrichtern anvertraut war, behandelten diese entsprechende Beschwerden gleich wie allgemeine Verwaltungsangelegenheiten, womit der verfassungsrechtlichen Dimension nicht genügend Rechnung getragen wurde und der Grundrechtsschutz entsprechend litt.

4. Den Richtern des Senates 10 des Bundesgerichtshofes kann in den hier dargestellten Verfahren kein gesetzwidriges Handeln vorgeworfen werden. Doch ist festzuhalten, dass sie die Spielräume, die ihnen das Gesetz ließ, nicht zugunsten der Pressefreiheit und der Vereinsfreiheit ausnützten, sondern die sehr offenen Gesetzesformulierungen in derselben Weise wie die Polizeibehörde auslegten und damit zu einer sehr restriktiven, mit der Ideologie des Regimes konformen Interpretation kamen. Über die poli- 
tische Rolle, die sie dabei spielten, waren sich die Richter, wie die Beratungsprotokolle zeigen, völlig im Klaren. Ob persönliche Gründe, wie etwa, dass im Verfahren auch thematisiert wurde, dass der Beschwerdeführer ihr eigenes Erkenntnis aus 1935 kritisiert hatte, hier wenigstens unbewusst eine Rolle spielten, kann nicht nachgewiesen werden.

\section{Nachwort}

Josef Enslein blieb weiter im Untergrund aktiv und hielt Kontakt zu seinen Kollegen - während des „christlichen“ und während des „zweiten Faschismus", wie er es in seinen Erinnerungen beschrieb: „Manche Fäden wurden loser. Viele waren eingerückt, der Terror und die Bespitzelung wurden immer drückender. Als endlich die Befreiung kam, wurde ich am 16. April 1945 vom Bürgermeister beauftragt, das Volks- und Hauptschulwesen in Wien zu reorganisieren." So wuchs dem mittlerweile 75-jährigen in den ersten Tagen der Zweiten Republik eine überaus schwierige Aufgabe $\mathrm{zu}$, doch gelang es ihm „schon Ende Mai, fünf Wochen nach der Befreiung, den Unterricht in den nicht zerstörten Schulen wiederaufzunehmen." ${ }^{\prime 100}$

Bereits während dieser Zeit, am 27. April 1945, wurde Enslein von Karl Renner zum Mitglied der von ihm geleiteten Provisorischen Staatsregierung berufen. Als Unterstaatssekretär im Staatsamt für Volksaufklärung, für Unterricht und Erziehung hatte er knapp acht Monate lang, bis zum erstmaligen Zusammentreten des neu gewählten Nationalrates und der Ernennung der ersten Bundesregierung am 20. Dezember 1945, fast dieselbe Position inne, wie sie siebenundzwanzig Jahre zuvor Glöckel gehabt hatte ebenfalls unter Renner als Staatskanzler. Am

${ }^{100}$ ENSLEIN, Schulrat 4. Vgl. auch den Bericht in der ersten nach dem Krieg erschienenen Nummer der Freien Lehrerstimme 51 (1945) Heft 1, 4-5.
25. Mai fand dann auch wieder die erste Versammlung des Zentralvereins der Wiener Lehrerschaft statt, in dem Enslein wieder die Obmannschaft übernahm und als solcher auch die „Freie Lehrerstimme“ wieder zu neuem Leben erweckte. ${ }^{101}$

Am 5. Jänner 1952 starb Josef Enslein in Wien. Wenige Monate später wurde mit dem Bau einer neuen Hauptschule in Wien-Favoriten begonnen und im Oktober 1953 eröffnet, worauf der Wiener Gemeinderat beschloss, den Platz vor der Schule "Josef-Enslein-Platz" zu benennen. ${ }^{102}$ Seit dem Schuljahr 2003/04 nimmt diese Hauptschule am Schulversuch „Kooperative Mittelschule" teil, einem Projekt zum gemeinsamen Unterricht der Zehn- bis Vierzehnjährigen. ${ }^{103}$ Mutatis mutandis wurde damit ein Projekt verwirklicht, für das Glöckel und Enslein zu ihren Lebzeiten stets eingetreten waren.

\footnotetext{
${ }^{101}$ Das erste Heft erschien am 20. 7. 1945; vgl. ebd. den Bericht über die erste Versammlung auf S. 5. Bis zum Heft Nr. 4 aus 1946 wurden als Eigentümer/Herausgeber/Verleger der Zeitschrift sowohl der Zentralverein der Wiener Lehrerschaft als auch Josef Enslein angegeben. Vgl. auch STIMMER, Arbeiter von Wien 161.

102 STIMMER, Arbeiter von Wien 204; CZEIKE, Historisches Lexikon Wien III, 378.

${ }^{103}$ Vgl. dazu R. OLECHOWSKI, Vermeidung, mit weiteren Nachweisen.
} 


\section{Literatur:}

Oskar ACHS, Die Schulreform in der Ersten Republik (1918-1927), in: Österreich in Geschichte und Literatur 13 (1969) 223-235.

Oskar AcHS, Politische Bildung an Österreichs Schulen, in: Stefan KARNER, Lorenz MIKOLETZKY (Hgg.), Österreich. 90 Jahre Republik (Innsbruck-WienBozen 2008) 319-329.

Erik ADAM u.a. (Hgg.), Die Schul- und Bildungspolitik der österreichischen Sozialdemokratie in der Ersten Republik (Wien 1983).

Erik ADAM, Austromarxismus und Schulreform, in: ADAM, Schul und Bildungspolitik 271-416.

Klaus BERCHTOLD, Verfassungsgeschichte der Republik Österreich, Bd. 1: 1918-1933. Fünfzehn Jahre Verfassungskampf (Wien-New York 1998).

Fritz CSOKLICH, Presse und Rundfunk, in: WeINZIERL, SKALNIK, Österreich 1918-1938, 715-743.

Herbert DACHS, Austrofaschismus und Schule, in: TÁlos, NeUGEBAUER, Austrofaschismus 282-296.

Wolfgang DuchKOWITSCH, Das unfreie „Haus der Presse" - Zensur im "Ständestaat", in: Erika. WEINZIERL u.a. (Hgg.), Justiz und Zeitgeschichte, Bd. 2 (Wien 1995) 565-573.

Gertrude Enderle-Burcel (Hg.), Protokolle des Ministerrates der Ersten Republik, Bd.8/2 (Wien 1982).

Gertrude Enderle-Burcel u.a. (Hg.), Protokolle des Kabinettsrates der Provisorischen Regierung Karl Renner 1945, Bd. 1 (Wien 1995).

Helmut ENGELBRECHT, Lehrervereine im Kampf um Status und Einfluß. Zur Geschichte der Standesorganisationen der Sekundarschullehrer in Österreich (Wien 1978).

Helmut ENGELBRECHT, Geschichte des österreichischen Bildungswesens, Bd. 3 (Wien 1984), Bd. 5 (Wien 1988).

Josef ENSLEIN, Warum ich nicht Schulrat wurde, in: Freie Lehrerstimme 54 (1948) Heft 4, 4.

Hans FISCHL, Schulreform, Demokratie und Österreich (Wien 1950).

Everhard HOLTMANN, Autoritätsprinzip und Maßnahmegesetz. Zur verfassungsrechtlichen Stellung der Justiz im österreichischen Ständestaat, in: Die österreichische Verfassung von 1918 bis 1938 (Wien 1980) 210-222.

Hans KELSEN, Österreichisches Staatsrecht (WienLeipzig 1923).

Primus Heinz KUCHER, Zur Vorgeschichte des austromarxistischen Schul- und Bildungsprogramms, in: ADAM, Schul- und Bildungspolitik 137-270.
Peter MALINA, Bücherverbote in Österreich 1933-1938, in: Zeitgeschichte 10 (1982/83) 311-335.

Friedrich MeISTER (Hg.), Zusammenstellung der auf dem Gebiete des Pressewesens derzeit geltenden Vorschriften (Wien 21935).

Adolf MERKL, Die ständisch-autoritäre Verfassung Österreichs. Ein kritisch-systematischer Grundriß (Wien 1935).

Martina NUSSBAUMER, sozialistisch, christlich oder „neutral“? Vom Kampf um die richtige Bildung, in: Wolfang Kos (Hg.), kampf um die stadt. Kata$\log$ zur 361. Sonderausstellung des Wien Museums (Wien 2010) 79-86.

Richard OleCHOWSKI, Schulpolitik, in: WEINZIERL, SKALNIK, Österreich 1918-1938, 589-605.

Richard OLECHOWSKI, Schul- und Bildungspolitik während der Ersten und der Zweiten Republik, in: Erich ZÖLLNER (Hg.), Österreichs Erste und Zweite Republik (Wien 1985) 99-120.

Richard OLECHOWSKI, Die humanistisch orientierte Schulorganisation nach J. A. Comenius und die Gesamtschulidee des 20. Jahrhunderts, in: Erziehung und Unterricht 142 (1992) 428-435.

Richard OLechOWSKI, Vermeidung einer frühen Selektion - Gemeinsame Sekundarstufe I, in: Erziehung und Unterricht 155 (2005) 906-919.

Thomas OlechOWSKI, Die Entwicklung des Preßrechts in Österreich bis 1918 (Wien 2004).

Thomas OlechOWSKI, Der österreichische Bundesgerichtshof und seine Judikatur zum Religionsrecht 1934-1938, in: Österr. Archiv für Religionsrecht (2005) 88-106.

Thomas OlechOWSKI, Grundrechte und ihr Schutz in der Habsburgermonarchie, RZ 88 (2010) 30-37.

Peter PELINKA, Manfred SCHEUCH, 100 Jahre AZ (Wien-Zürich 1989).

Ilse REITER, Gustav Harpner (1864-1924). Vom Anarchistenverteidiger zum Anwalt der Republik (Wien-Köln-Weimar 2008).

Helmut RUMPLER, Der Ständestaat ohne Stände. Johannes Messner als "Programmator" der berufsständischen Idee in der Verfassung des Jahre 1923, in: Reinhard KRAMME u.a. (Hgg.), Der forschende Blick. Festschrift für Ernst Hanisch (Wien-KölnWeimar 2010) 229-245.

Heinrich SALFENAUER, Der Zentralverein der Wiener Lehrerschaft von seiner Gründung bis 1934 (phil. Diss. Salzburg 1978).

Anton SIMONIC, Heimat und Vaterland als Wertbegriffe in der Pädagogik, in: Pädagogischer Führer 85 (1935) 496-504.

Kurt STIMMER, Die Arbeiter von Wien (Wien 1988). 
Theodor STEISKAL, Otto Glöckel. Die österreichische Schulreform, in: Pädagogische Blätter 2 (1935) Heft 10, 141-148.

Emmerich TÁLOS, Wolfgang Neugebauer (Hgg.), Austrofaschismus (Wien ${ }^{52005) . ~}$

Helmut UITZ, Die österreichischen Kinderfreunde und roten Falken 1908-1938 (Wien-Salzburg 1975).

Erika WeINZIERL, Kurt SKALNIK (Hgg.), Österreich 1918-1938. Geschichte der Ersten Republik, Bd. 2, (Graz-Wien-Köln 1983).

Heinz WEISS, Das rote Schönbrunn. Der Schönbrunner Kreis und die Reformpädagogik der Schönbrunner Schule (o.O. [Wien] 2008).

Max WINTER, 10 Jahre. Erinnerungsbilder aus dem Werden des Vereines „Freie Schule - Kinderfreunde" von den Anfängen bis zum zehnjährigen Gründungstag des Reichsvereines (Wien 1927).

Helmut WoHNOUT, Regierungsdiktatur oder Ständeparlament? Gesetzgebung im Autoritären Österreich (Wien-Köln-Graz 1993).

Helmut WOHNOUT, Anatomie einer Kanzlerdiktatur, in: Hedwig Kopetz u.a. (Hgg.), Soziokultureller Wandel im Verfassungsstaat. FS Mantl (WienKöln-Graz 2004) 961-975.

\section{Abkürzungen:}

AdR Österreichisches Staatsarchiv - Archiv der Republik, Wien

AVG Allgemeines Verwaltungsverfahrensgesetz

KwEG Kriegswirtschaftliches Ermächtigungsgesetz

StPAH Stenographische Protokolle des Abgeordnetenhauses

Siehe auch das allgemeine Abkürzungsverzeichnis: http://www.rechtsgeschichte.at/beitraege/abk.pdf 